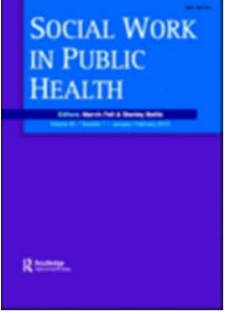

\title{
Socioeconomic Status, Family Functioning and Delayed Care Among Children With Special Needs
}

\begin{tabular}{|c|c|}
\hline Journal: & Social Work in Public Health \\
\hline Manuscript ID & WHSP-2017-0130 \\
\hline Manuscript Type: & Original Article \\
\hline Keywords: & social support, children with special needs, socioeconomic, delayed care \\
\hline
\end{tabular}




\begin{abstract}
34 Abstract
35 Parents of children with special healthcare needs (CSHCN) face tremendous stress in caring for

36 their children. Families of CSHCN face increased barriers to health services as evidence also

37 reflects the influence of socioeconomic factors on access. This study investigates the impact of

38 socioeconomic factors and family functioning on delayed care. Descriptive, bivariate, and

39 adjusted multivariate logistic regression were performed using sampling weights. Our findings

40 suggest that family dynamics are more impactful on delayed care than socioeconomic predictors.

41 Promoting family-centered care that incorporates social support for families to reduce barriers is

42 essential for improved quality of life and health outcomes.
\end{abstract}

43 Keywords: social support, children with special needs, delayed care, socioeconomic

44

45

46

47

48

49

50

51

52

53

54

55

56

57

58

59

60

61 
62

63

64

65

66

67

68

69

70

71

72

73

74

75

76 77 Lotstein, 2013).

78

79

80

81

82

83

84

\section{Introduction}

An estimated 11.2 million children under the age of 18 in the US have special health care needs, representing about 23 percent of U.S. households with children that have at least one child with special health care needs (Caicedo, 2014; U.S. Department of Health and Human Services Health Resources and Services Administration - Maternal and Child Health Bureau, 2013). The Bureau of Maternal and Child Health defines special healthcare needs (CSHCN) as; 1) a child who has a compendium of "chronic physical, developmental, behavioral, or emotional conditions that require health and related services of a type, or 2) amount of health and related services beyond that required by children generally" (Benevides, Carretta, \& Mandell, 2016; Burns et al., 2010; Kuhlthau, Kahn, Hill, Gnanasekaran, \& Ettner, 2010; D. Z. Kuo \& Houtrow, 2016; Pollard et al., 2014). Children with special needs have long been designated a priority population for health care policy (D. Z. Kuo \& Houtrow, 2016; McPherson et al., 1998; US Department of Health and Human Services, 1987), yet disparities in care remain. Health outcomes increasingly become more favorable for $\mathrm{CSHCN}$ in recent years, which in turn translates to population growth for adults with special health care needs in the long term (Okumura, Hersh, Hilton, \&

Children with special health needs require special and constant access to medical services so that the child can develop into an otherwise healthy adult and maintain a quality of life with dignity. The range of health and medical services include therapies, home healthcare, prescription drugs, mental healthcare, medical equipment, and dental services (Rosen-Reynoso et al., 2016). Many children with special needs, healthcare services are either partially covered or not covered by insurance plans. This leaves many families to fund the remaining portion of healthcare costs. In additionally, most of the families have household incomes fall below the 
85 federal poverty line. In particular, parents of children with activity limitations or special

86 healthcare needs have lower employment and increased work absences than other parents

87 (Kuhlthau et al., 2010). Furthermore, families of CSHCN experience greater financial stress than

88 families of children without CSHCN (Goudie, Narcisse, Hall, \& Kuo, 2014). Additionally,

89 families of children with chronic conditions experience more out-of-pocket costs than families of

90 unaffected children (Kuhlthau et al., 2010; Resch et al., 2010). On average, approximately $22 \%$

91 of families with children with special needs spend more than $\$ 1,000$ out-of-pocket on healthcare

92 services with another $12 \%$ of CSHCN families spending between $\$ 501$ and $\$ 1000$ on healthcare

93 services annually (U.S. Department of Health and Human Services - Health Resources and

94 Services Administration - Maternal and Child Health Bureau, 2013). As a result, parents of

95 children with special healthcare needs are more likely to report unmet healthcare needs than

96 parents of children without these healthcare needs, particularly if the child is affected by two or

97 more conditions (Schieve et al., 2012). Consequently, "children and youth with special health

98 care needs and their families often need services from multiple systems - health care, public

99 health, education, mental health, and social services" (Health Resources and Services

100 Administration, 2016).

101 Caring for children with special health care needs requires more effort and resources, to

102 overcome barriers to care than caring for children without these conditions, which can make

103 coping with their diagnosis emotionally draining (Ammari, Morris, \& Schoenebeck, 2014). In

104 August 2016, the US Social Security Administration and Institute of Medicine requested that the

105 National Academies of Sciences, Engineering, and Medicine convene an ad hoc committee to

106 study health outcomes among school-aged children with disabilities (National Academy of

107 Sciences, 2017). In particular, the committee was charged with examining the congruency of 
108 programs, services, and support systems available to children with disabilities children and their 109 families. Further, the Committee has a broad scope which includes; examining utilization rates 110 for existing services and health programs. At the time of our study, the Committee has yet to 111 issue its report. The study reported on here therefore is in line with the overarching goals and 112 vision of the Maternal Child Health Bureau (MCH) at the Health Resources and Services 113 Administration (HRSA), which aims for optimal health and quality of life for all children and 114 youth with special health needs and their families.

115 Numerous studies have identified family relationship dynamics and functioning and 116 parental coping mechanisms for dealing with the stresses of a child's health condition as potent 117 predictors of the child's wellness and adaptation to the chronic health conditions (Churchill, 118 Villareale, Monaghan, Sharp, \& Kieckhefer, 2010; Geist, Grdisa, \& Otley, 2003). Evidence from 119 some of these studies suggest that parents of CSHCN typically report higher rates of stress 120 compared to parents of children without special health needs (Estes et al., 2013; Hayes \& 121 Watson, 2013; Neece, Green, \& Baker, 2012). Additionally, some of these parental stressors 122 among children with special healthcare needs have greater negative effects on the quality of child 123 care than variables such as income, time available for a child, and social support when trying to 124 predict parenting stress, better than the child's functional abilities (Ammari et al., 2014). Higher 125 levels of stress have been reported among parents of younger children with special healthcare 126 needs (Neece et al., 2012; Sipal, Schuengel, Voorman, Van Eck, \& Becher, 2010). Neece (2012) 127 concluded that there is a transactional relationship between parental stress and child behavior 128 problems. Caring for a child with behavioral problems exerts increased stress on parent, which 129 can complicate the parent's ability to care for the child, including facilitating access to health 130 care services. When the child has a parent or caregiver who is chronically stressed, it complicates 
131 parental ability to appropriately cater to the needs of the child especially one with disabilities

132 which further exacerbates the child's behavioral problems (Neece, 2014; Neece et al., 2012).

\section{Conceptual framework}

134

135

136

137

138

139

140

141

142

143

144

145

146

147 arrows as follows:

$148 \quad$ Domain 1: Adult/parental mental illness

149 Domain 2: Child mental health and development

150 Domain 3: Family relationships (parenting \& marital interactions)

$151 \quad$ Domain 4: Risk \& protective factors

152 Domain 5: Services for children \& adults

153 Domain 6: Cultural \& community influences 
154 In short, Falkov's conceptual model, which is described was adopted in this study to 155 facilitate scaffolding and understanding of the issues under investigation, while delineating clear 156 parameters and boundaries for the entire study (Creswell, 2009; Miles \& Huberman, 1994;

157 Miles, Huberman, \& Saldaña, 2013).

158

Previous studies have focused solely on the effect of socioeconomic factors on access to care for CSHCN. In addition to socioeconomic factors that influence access to care, we examine and compare characteristics of CSHCN and their family dynamics with delayed health care. In order to answer the research question, we posed three hypotheses as follows:

1. Children with special health care needs are more likely to experience delayed medical care than other children;

2. Children from families in the higher socioeconomic classes will be less affected by delayed care; and

3. Family functioning will have a significant effect on delayed health care among children with special healthcare needs.

\section{Methods}

170 Design and Study Population

171 This research study utilizes data from the 2011-2012 National Survey of Children's Health 172 (NSCH), funded by the U.S. Department of Health and Human Services, Maternal and Child 173 Health Bureau. The NSCH provides cross-sectional data on multiple, intersecting aspects of 174 children's lives-including physical and mental health, access to quality healthcare, and the 175 child's family, neighborhood, school, and social context (Data Resource Center for Child and 176 Adolescent Health, n.d.). Data collection were conducted through random selection of United 
177 States telephone numbers which are further screened to identify households with one or more 178 children under the age of 18 (Silverberg, Joks, \& Durkin, 2014). Surveys were conducted by the 179 National Center for Health Statistics at the Centers for Disease Control, with interviews in 180 English, Spanish, Korean, Mandarin, Cantonese, and Vietnamese (Silverberg et al., 2014).

\section{Dependent Variable}

The outcome variable for our study is, "delayed use of healthcare services by children with special needs." Parents of the children with special health care needs were asked, "During the past 12 months, was there any time when [CHILD's NAME] needed health care but it was 185 delayed or not received?" A 'yes' response was considered delayed healthcare and coded as '1' 186 while a 'no' response was coded '0" signifying met needs.

\section{Independent Variables}

The independent variables comprised of the socio-demographic variables including age, 189 sex, race/ethnicity, parental employment, insurance, and Medicaid or SCHIP coverage. Need 190 variables included having a doctor recommendation for treatment or counseling, a doctor 191 recommendation for the child to see a specialist, an index child having behavioral problems, the 192 child needed mental health services, autism, developmental delay and intellectual delay), 193 socioeconomic variables. Parental characteristics included: parental frustration, positively coping 194 with the demands of caring for a child with specials needs, problems paying medical bills, and 195 parental social support. Specifically, parental social support was defined as having someone to 196 whom the parent or caregiver can turn to for day-to-day emotional with fulfilling the 197 responsibilities of parenthood or raising a child with special needs. The familial variable was 198 coded as ' 1 ' if a support system existed and '0' otherwise.

199 Data Analysis Methods 
We computed descriptive, frequencies for categorical variables and mean (SD) and

201 bivariate proportions for the covariates and outcome variables respectively. Data were weighted

202 to account for the complex sampling design and weighting procedures. Stata software packaged

203 version 14 for Windows, (Stata Corp Inc., College Station, TX) was used for all the analysis,

204 with an alpha of 0.05 for significance level. We computed frequencies and percentages for

205 categorical variables (see Table 1). We performed a Chi-square test to find the association and

206 significance between each covariate and delayed care for characteristics of CSHCN,

207 socioeconomic factors, and family dynamics (see Tables 2, 3, and 4). Tables 2, 3, and 4 also

208 include bivariate regression analyses to estimate the odds of each covariate and delated care.

209 Finally, we computed multivariate logistic regressions to estimate the adjusted odds of delayed

210 care while adjusting for cofounders (Tables 2, 3, and 4).

\section{Results}

212 The results of our study are presented in three sections addressing, descriptive, bivariate

213 and multivariate results. Tables 1 contains the univariate weighted proportions of the covariates,

214 while Tables 2, 3, and 4 breakdowns the results of the bivariate and multivariate analysis by

215 sociodemographic, health care utilization and need domains.

\section{Descriptive}

217 The sample means age was $10.98(\mathrm{SD}=4.39)$ years of age; $37.2 \%$ were female and

$21862.8 \%$ were male. The majority of the sample was White (67.6\%), $15.6 \%$ Black, and $16.8 \%$

219 were other minorities (Table 1 below). A significant proportion of the children in the study had

220 health insurance coverage (96.3\%), 90.3\% had a regular doctor, and $93.3 \%$ saw a doctor in the

221 12-month period preceding the interview. It is important to note that $52.3 \%$ of the sample had

222 Medicaid or State Children's Health Insurance Program (SCHIP) for insurance coverage. Our 
223 study shows that the proportion of our sample that needed treatment or counseling was $34.4 \%$

224 and $28.5 \%$ had a parent who self-reported a behavior problem. Unfortunately, there were $48.6 \%$

225 who did not see a mental health care professional during the period preceding the interview

226 despite having behavior problems or needing treatment or counseling. At the state level,

227 Medicaid and SCHIP funding for mental health care services are limited (Behrens, Lear, \& Price,

228 2013). These differences in coverage and utilization of services suggest a gap or lack of mental

229 health services for children receiving government-funded health insurance. The differences may

230 be a result of state Medicaid programs that have separate contracts for behavioral health services;

231 leading to fewer mental health care providers (Chiri \& Warfield, 2012).

232 [Insert Table 1 here]

233 Characteristics of CSHCN and Delayed Care

$234 \quad$ Bivariate analysis.

235 Weighted results of the bivariate and multivariate analyses are presented in Table 2 for

236 characteristics of CSHCN and delayed care. Overall, there were significant differences in

237 CSHCN (16.5\%) who experienced delayed health care than children without special needs

238 (1.9\%). Similarly, higher proportions of children with special needs who saw a mental health

239 care professional experienced a delay in care than those who did not $(7.3 \%)$. We found there was

240 were significantly lower differences for children who needed treatment/counseling (8.5\%), had

241 behavior problems (6.3\%), and a doctor said the child needed to see a specialist (4\%) with

242 delayed care $\left(\chi^{2}=20.9 ; \mathrm{p}<0.001, \chi^{2}=6.68 ; \mathrm{p}<0.01\right.$, and $\chi^{2}=41.3 ; \mathrm{p}<0.001$ respectively).

243 No statistically significant differences were found among CSHCN who had either autism,

244 developmental or intellectual delays.

$245 \quad$ [nsert Table 2] 


\section{Socioeconomic Factors and Delayed Care}

Bivariate analysis.

248 Results also suggest higher proportions of delayed care for our sample with each socioeconomic

249 factor defined (see Table 2). These differences in proportion were only statistically significant

250 for parent's employment status and having health insurance in the 12-month period preceding the

251 interview $\left(\chi^{2}=45.0 ; \mathrm{p}<0.001\right.$ and $\left.\chi^{2}=12.7 ; \mathrm{p}<0.001\right)$ respectively.

252 [Insert Table 3]

\section{Family Functioning and Delayed Care}

254 Consistently research has shown that family functioning has a significant impact on the health 255 and quality of life of children with special needs. All were statistically significant in the bivariate 256 analysis (see Table 2). Each predictor suggested higher proportions with the expectation of the 257 family having problems paying medical bills, which results showed similar proportions between

258 families who did $(8.8 \%)$ and did not $(8.9 \%)$ have problems paying $\left(\chi^{2}=82.1 ; \mathrm{p}<0.001\right)$.

259 Multivariate analysis.

260 At the multivariate level, several factors were significantly associated with delayed care

261 in children with special needs at the adjusted level predictor suggested a higher likelihood of

262 delayed care with the expectation of children with behavioral problems. In general, CSCHN

263 were statistically two times more likely (AOR $=2.00 ; \mathrm{CI}$ : 95\% $1.10-3.61)$ to have delayed care

264 than children without special health care needs. Children with special healthcare needs and a

265 diagnosis of autism experienced delayed care more often (57\%) CSHCN who did not have

266 autism $(\mathrm{AOR}=1.57$; CI: 95\% 1.06-2.32). $\mathrm{CSHCN}$ who received treatment or counseling in the

267 12-month period preceding the interview were significantly more likely to have had delayed care

$268(\mathrm{AOR}=1.81 ; \mathrm{CI}: 95 \% 1.08-3.04)$. Ironically, CSHCN who had a recommendation to see a 
269 specialist were three times $(\mathrm{AOR}=3.09$; CI: $95 \% 2.03-4.71)$ to experience a delay in care than 270 CSHCN who were not recommended.

271 Results of the multivariate analysis suggest that children whose parents report frustration 272 are significantly more likely to have delayed care (AOR $=7.68$; 95\% CI: 5.06-11.6.

273 Additionally, children whose parents report difficulty paying bills also experience significant 274 delays in critical healthcare services $(\mathrm{AOR}=2.17 ; 95 \% \mathrm{CI}: 1.52-3.09)$. Children with special 275 needs whose parents self-reported positively coping with parenthood were $14 \%$ less likely 276 experienced delayed care in the 12 -month period preceding the (AOR $=0.86$; 95\% CI: 0.48 277 1.53). For parents who had social support, lower odds of delayed care were observed, but results 278 were only significant at the bivariate level.

$279 \quad$ [Insert table 4].

280 At the multivariate level, those with insurance were $66 \%$ less likely to have had delayed care $281 \quad(\mathrm{AOR}=0.34 ; \mathrm{CI}: 95 \%$ 0.15-0.73). Medicaid or SCHIP recipients were nearly two times more 282 likely to experience delayed care (AOR = 1.96; CI: 95\% 1.32-2.92). Having a regular doctor and 283 seeing a doctor also led to higher chances of delayed access and use of healthcare services. 284 However, these differences were not statistically significant.

\section{Discussion}

286 The aim of this study was to examine the impact of characteristics of CSHCN, 287 socioeconomic factors, and family dynamics on delayed care for CSHCN. Expanding on the 288 knowledge from previous studies, we hypothesized that the impact of delayed care would be 289 higher for CSHCN, socioeconomic factors would decrease delayed care for families with 290 favorable statuses, and that family dynamics would have similar effects on delayed care for 291 CSHCN as the relationship between socioeconomic factors and access to care. Our first 
292 hypothesis was proven true, as higher proportions and odds of delayed care were observed. As 293 expected, socioeconomic factors suggested very traditional implications for delayed care. For 294 example, parents who worked or parents of children with health insurance were less likely to 295 experience delayed care. One explanation for this difference could be that their parents can 296 afford private insurance to supplement care that is not covered by government-funded health 297 care, thus decreasing the chance of delayed care (Krauss, Gulley, Sciegaj, \& Wells, 1993). 298 Based on previous research as well as the results of the current study, our first hypothesis 299 that CSHCN would have more delays in medical care due to their diagnosis than children 300 without special health care needs was validated. This is also consistent with the conceptual 301 framework of this study in that the evidence suggests that having CSHCN impacts on the 302 parents' ability to respond to their health needs by acting as stressors and reducing parents' 303 resilience and protective ability. From these finding, we can infer that the mental health of adults 304 with childcare responsibilities are affected by CSCHN and therefore should be acknowledged as 305 a global public health issue requiring a greater focus on individuals within their family context. $306 \quad$ Key findings of our study suggest that delayed care was still a persistent issue for 307 CSCHN although in recent years there has been an increase to resolve challenges and barriers to 308 care for people with disabilities. Additionally, we found that the proportions of diagnosis 309 (autism, developmental delays, or intellectual delays) varied at the bivariate level, but the 310 likelihood of having delayed care was higher for children who had autism or an intellectual delay 311 about both the bivariate and multivariate levels. However, the three diagnosis-related predictors 312 were not found to be statistically significant except autism at the multivariate level. This could 313 reflect stigmas associated with autism and should be researched further. 
Surprisingly, CSHCN who had a doctor say they needed to see a specialist were over

315 three times as likely to have had delayed care at both the bivariate and multivariate levels. Often

316 is it easier to access a specialist with a referral from a primary care physician (Dunlea \& Lenert,

317 2015; van Dijk, Korevaar, Koopmans, de Jong, \& de Bakker, 2014) and many insurance plans

318 require one. This finding may suggest that there is a strong disconnect for CSHCN with referrals

319 to specialty care. It also circles back to echo known barriers of access to care that were

320 previously mentioned. To be clear on this issue, we suggest that future research should show if

321 this is a direct effect of time between referrals from doctors to specialist or if it is lack of

322 specialty care professionals for people with disabilities. Another reason there for a delay in care

323 after a referral is that adding more professionals to a care plan can make decisions about

324 treatment options more difficult for parents (Stille et al., 2013). Also, for those who were able to

325 see a mental health care professional in the selected timeframe, the likelihood to experience to

326 have delayed care was $69 \%$ less likely, leaving more than a quarter (31\%) of the sample with the

327 likelihood of delayed care. While these children eventually did see a mental health care

328 professional, there was still a great chance that they were not able to see them in a timely

329 manner.

330 Socioeconomic Factors

331 Evidence from this study suggest that adverse socio-economic factors can be stressors

332 which lead to delayed access to care for parents and families with CSHCN, even though this is to

333 a lesser extent compared to the influence of social support, family relationship dynamics and

334 functioning. Ironically, children who had health care coverage in the 12-month period preceding

335 the interview were $66 \%$ less likely to have delayed care than those children without special

336 healthcare needs with no coverage. However, for those who specified being enrolled in Medicaid 
337 or SCHIP only, results suggest lower rates of delayed care. CSHCN who were enrolled in 338 Medicaid or SCHIP were twice as likely to experience delayed care compared to children 339 without special needs who were enrolled. Szilagyi (2012) cited provider reimbursement for 340 government-funded insurance tended to be lower than private insurer reimbursement; making 341 some providers reluctant to care for the publicly insured, particularly children who have public 342 insurance and are at high-risk.

343 Other socio-economic factors that contribute to delayed care among children with special 344 needs include; out-of-pocket cost, provider lack of knowledge and experience in providing care 345 for disabled children, inadequate equipment, and discrimination (Ali et al., 2013; Krahn, Walker, 346 \& Correa-De-Araujo, 2015). These findings are consistent with the conceptual framework for 347 this study which acknowledges that complex health needs for children have implications for 348 resources and support services which are affected by external factors, such as cultural, 349 community or socio-economic ones.

350 Understanding the role of these factors and the potential negative effect they have on the 351 ability of CSHCN's ability to access critical care services is important for public health social 352 workers. Resolving these issues is important because most CSHCN will rely on publicly-funded 353 health care into adulthood (Okumura et al., 2013)and people with disabilities are entitled to the 354 same health equity and opportunities as people without disabilities.

355 Results from this study suggest that family functioning had a greater influence on delayed 356 care than socioeconomic predictors. Parents of CSHCN experience significant stress and 357 frustration as demonstrated in our findings and previous studies. Falkov's Family Model alludes 358 to the effect family stress arising out of health issues for either or both children and parents 359 having the potential to negatively impact on family relationships and functioning (Falkov, 2012). 
360 Evidence from this study shows that parents who coped positively with raising CSHCN were less

361 likely to have delayed care for their children. Coping is a proactive, practice that encompasses a

362 combination of behavioral, emotional, and cognitive attempts to help manage the distress

363 brought on by the stressor (Zaidman-Zait et al., 2017). Traditionally and culturally, mothers are

364 the primary caregivers of their children (Neves et al., 2013; Pridham, Limbo, \& Schroeder,

365 1998). Woodman (2013) set out to assess the role of coping strategies for depressive symptoms

366 and parenting efficacy outside of socioeconomic factors, characteristics of their children, and

367 adolescent behavioral problems for mothers with adolescents with developmental disabilities.

368 Similar to this current study, the results suggested socioeconomic status did not produce a

369 significant change in maternal depressive symptoms or parenting efficacy (Woodman \& Hauser-

370 Cram, 2013). Finally, after longitudinal analysis of both problem-focused and emotion-focused

371 coping strategies, Woodman (2013) concluded that coping indeed plays a role in maternal well-

372 being over time. Consistent with findings from Woodman parenting and family functioning, are

373 significantly associated with lower odds of delayed care is decreased when family functioning

374 when parents of CSHCN have positive experiences with coping.

375 Social support, family relationship dynamics and functioning and delayed care

376 Family structure, including social support and social network, has been shown to mediate

377 the burden experienced by families with special needs (DeHoff, Staten, Rodgers, \& Denne,

378 2016). The evidence presented from this study on positively coping, in conjunction with findings

379 for parental social support, suggests that having positive family relationships and social support

380 contribute to fewer instances of delays in care for CSHCN. Evidence from this study, as with

381 previous studies shows that parents of CSHCN self-reported high levels of frustration or stress

382 (Kissel \& Nelson, 2016; Neece, 2014). Social support has been linked to not only effective 
383 coping behaviors, but other positive health statuses such as a sense of stability, psychological 384 well-being, and perceived control among others for parents of CSHCN (Langford, Bowsher, 385 Maloney, \& Lillis, 1997; Peer \& Hillman, 2014). Furthermore, social support has also been 386 defined as an interpersonal transaction between emotional and instrumental dimensions (Norona $387 \&$ Baker, 2014) that is one of the best coping mechanisms for parents of CSHCN (Findler, Klein 388 Jacoby, \& Gabis, 2016; Zaidman-Zait et al., 2017).

389 When parents do not have any means of social support, stressful situations may impact 390 susceptibility to increased psychological distress, emotional and functional problems, and 391 illnesses (Findler et al., 2016). Parenting CSHCN can also have a negative effect on other family 392 relationship dynamics such as finding appropriate and affordable child care, making work 393 decisions, obtaining education/training, having additional children, problem-solving, and relying 394 on government-funded insurance (Reichman, Corman, \& Noonan, 2008; Zaidman-Zait et al., 395 2017).

396

As mentioned previously, parents of children with special needs often face more financial 397 burdens associated with child care than parents of children without special needs. Evidence from 398 this study shows that parents self-reported that when they had problems paying medical bills, 399 they were over 4 times more likely to have delayed care at the bivariate level and over two times 400 more likely at the multivariate level (AOR $=4.11 ; 95 \%$ CI: $2.99-5.66, \mathrm{p}<0.001)$. Possible 401 explanations of this finding could stem from parents having to make their children skip or 402 postpone appointments for reasons such as disagreement with new treatment plans, the 403 consequences associated with treatment, a belief that the benefits do not outweigh the cost, not 404 retrieving prescribed medication in a timely manner, or avoiding additional medical costs due to 405 lack of funds (Cameron et al., 2014). Although many CSHCN are covered by government- 
406 funded programs that reimburse providers a significant portion of the costs, there are still

407 considerable amount of out-of-pocket expenses that are not covered (Barrett et al., 2015). The

408 out-of-pocket costs leave many families with limited means for providing needed care to their

409 children.

410 Social support, relationship dynamics and functioning can be instrumental in terms of

411 health care when parents are supported with various healthcare-related activities such as

412 investing in time to make their child's appointment on time, finding doctors who are capable of

413 care for CSHCN, assisting with transportation, or helping understand and adjust to new treatment

414 plans (Caicedo, 2014). Children whose parents or caregivers have social support are less likely to

415 experience delays in health care (McKenzie, Ouellette-Kuntz, Blinkhorn, \& Démoré, 2017; Van

416 Cleave, 2015). Parents with social support gain understanding and develop the ability to care for

417 and be advocates for their children (DeHoff et al., 2016). Social support, along with positive

418 family relationship dynamics, are critical because they assist parents in maintaining functioning

419 and stability for their family and balance in their own lives (Peer \& Hillman, 2014).

420 Parallels can therefore be drawn between the findings of this study and Falkov's model in

421 that, in both, the child's mental health and special health care needs, there is a transactional

422 relationship between parental stress and child health and behavioral difficulties (Domain 1 and

423 2). As with this study, Falkov (2012) argued that the family relationship dynamics and

424 functioning are influenced by the stress of a child's health condition and parental stress (Domain

425 3). As evidence from this study suggests, difficult family relationship dynamics and functioning

426 have significant implications for delaying access to health care for CSHCN and behavior

427 difficulties. These difficulties which are associated with their broader special health care needs or

428 mental health issues could lead to increased parental stress, difficult family relationship 
429 dynamics, and potentially adult mental health, which, as evidence from this study shows, further 430 exacerbates the development of the child's behavior problems due to delayed access medical 431 care for CSHCN. In both instances, this complicates parental ability to appropriately access 432 health care timely and meet needs of the children who have either special health care needs or 433 mental health needs. As with the Falkov's conceptual framework, therefore there are 434 implications for support services for both children and adults, resilience, protective factors, and 435 resources (Domain 4), for this study too, that determine the timely access to health services for 436 both children and adults (Domain 5). The influence of culture and community services (Domain 437 6) in the Falkov's conceptual framework can be likened to external factors such as the impact of 438 the family's culture and socio-economic influences on CSHCN access to services, which this 439 study also set out to investigate. Based on findings and the links made with Falkov's Family 440 Model a conceptual model for this study in relation to the transactional relationships between 441 multilevel influences to access to health services for CSHCN can be presented in Figure 1.

442 [Insert Figure 1: A Family-Centered Model for delayed care for children with special health 443 needs]

444 Although similar in many respects, what makes the proposed Family-Centered Model for 445 delayed care for children with special health care needs different from the Falkov's family model 446 is that more specifically, this model is about children with special health needs and mental health 447 needs. In line with the findings of the study, the proposed model emphasizes the centrality of 448 family relationship dynamics and functioning, social support and socio-economic factors in 449 influencing children's special health care needs and the special support needs for the caregivers 450 concerning access to support services. While the social support and other resources can act as a 451 protective factor and a source of resilience, adverse economic factors on the other hands can act 
452 as stressors that heighten risks for both caregivers and children with special health care needs.

453 Yet, in line with Falkov's family model, the proposed Family-Centered Model, as evidence from

454 this study suggests, both specialized services for children with special health care needs and

455 specialized support services for parents and caregivers would be in turn be influenced by external

456 factors such as the cultural parenting practices and available community resources. This is

457 consistent with assertions made earlier with regards to a large body of literature that shows that

458 culturally mothers are the primary caregivers of their children (Neves et al., 2013; Pridham et al.,

459 1998). As discussed in the section below, a number of implications for practice for delayed care

460 for children with special health care needs can therefore be drawn from the findings of this study.

$461 \quad$ Implications for Practice, Policy, and Research.

462 Children with special health needs are particularly vulnerable to complex medical

463 problems. These problems can be compounded by the lack coherence in family, community and

464 health systems resources and infrastructure. We recommend that healthcare providers and social

465 workers include features of social support into care coordination for CSHCN. Based on our

466 results, it would be beneficial for healthcare providers and social workers work together to

467 incorporate family-centered care programs by promoting family advisory boards and family/peer

468 support groups, family presentations on care experiences, and hiring family members as

469 consulting staff to specific programs (Dennis Z. Kuo et al., 2012). Because social workers are

470 very knowledgeable on how to interact with many types of families (Ferguson, 2016), it would

471 be ideal for them to expand on their roles with implementing care coordination and family-

472 centered care plans (Algood, Harris, \& Sung Hong, 2013). These types of programs are ideal for

473 families that do not have support from biological family members, and those who may be the

474 first in their family history to seek care for CSHCN. Some hospitals have proven to be successful 
475 by incorporating family-centered care programs and encourage family leaders to participate in

476 family advisory boards or peer support groups (Dennis Z. Kuo et al., 2012). Utilizing social

477 workers and other mental health clinicians beyond the diagnosis period can provide therapeutic

478 opportunities to facilitate stress management and provide support for parents as they navigate

479 complex medical systems and limited resources. Additionally, this study supports the finding of

480 reimbursement discrepancies between government and private health insurers. We would

481 encourage legislative officials, lobbyists, and advocacy groups to push for financial parity

482 regarding mental health reimbursements to ensure children receive quality care that may be vital

483 to their developmental well-being. Additional legislative action should be focused on increasing

484 resources for children and families with special health care needs. Further, coordination of

485 resources for families and children with special health needs would also alleviate some of the

486 burdens and ease the transition into needed care. Furthermore, continued research should

487 examine the long-term effects of programs that include family social support as it relates to the

488 occurrence of care delays.

489 Limitations of the study.

490 First, NSCH is dependent upon the parents' ability to report a diagnosis of their children

491 rather than using medical records (Chiri \& Warfield, 2012). Although parent report has been

492 shown to be a reliable measure of healthcare quality, there was no way to verify the information

493 (Chiri \& Warfield, 2012; Zuckerman, Lindly, Bethell, \& Kuhlthau, 2014). Second, the NSCH

494 does not have any measures to account for the severity of the children's diagnosis, which can

495 lead to misleading results especially for children on the autism spectrum. Third, the survey only

496 reaches households with landline telephones, which decreases the number of participants.

497 Finally, our study uses specific data for intellectual delays, developmental delays, and autism, 
498 but lumps all other special care needs such as cerebral palsy and schizophrenia. Despite these

499 limitations, this study still gives important insight on the impact of characteristics of CSCHN,

500 risks and stressors from socio-economic factors, social support as a protective and resilience

501 factor and a resource, and family dynamics in relations to delayed care for children with special 502 needs.

$503 \quad$ Conclusion

504 This study contributes to our understanding of the difference in socioeconomic factors 505 and family dynamics on delayed care for CSHCN. Collectively, our findings provide evidence 506 to parental social support positively influencing the outcome of delayed care. Having delays in 507 can add to the frustration and stress of parenting CSHCN. Experiences with parental social 508 support appear to be important constructs for coping with common life stressors of parents with 509 CSHCN. We conclude that family relationship dynamics have a greater impact on delayed care 510 than socioeconomic factors. A more family-centered approach that ensures that parents have 511 social support and can cope with caring for their children in turn decrease delays in care is 512 required. The use of qualified mental health professionals who understand the systemic interplay 513 of factors described in the proposed family-centered model' can positively affect family support 514 reducing the presence of care delays. 
522 References

523 Algood, C. L., Harris, C., \& Sung Hong, J. (2013). Parenting Success and Challenges for

524 Families of Children with Disabilities: An Ecological Systems Analysis. Journal of Human

525 Behavior in the Social Environment, 23, 126-136.

526 http://doi.org/10.1080/10911359.2012.747408

527 Ali, A., Scior, K., Ratti, V., Strydom, A., King, M., \& Hassiotis, A. (2013). Discrimination and

528 Other Barriers to Accessing Health Care: Perspectives of Patients with Mild and Moderate

529 Intellectual Disability and Their Carers. PLoS ONE, 8(8), e70855.

530 http://doi.org/10.1371/journal.pone.0070855

531 Ammari, T., Morris, M. R., \& Schoenebeck, S. Y. (2014). Accessing Social Support and

532 Overcoming Judgment on Social Media among Parents of Children with Special Needs.

533 International AAAI Conference on Weblogs and Social Media, 22-31.

534 Barrett, B., Mosweu, I., Jones, C. R., Charman, T., Baird, G., Simonoff, E., ... Byford, S. (2015).

535 Comparing service use and costs among adolescents with autism spectrum disorders, special $536 \quad$ needs and typical development. Autism, 19(5), 562-569.

537 http://doi.org/10.1177/1362361314536626

538 Behrens, D., Lear, J. G., \& Price, O. A. (2013). Improving Access to Children’ s Mental Health

539 Care: Lessons from a Study of Eleven States. Himmelfarb Health Sciences Library.

540 Retrieved from http://hsrc.himmelfarb.gwu.edu/sphhs_prev_facpubs

541 Benevides, T. W., Carretta, H. J., \& Mandell, D. S. (2016). Differences in Perceived Need for

542 Medical, Therapeutic, and Family Support Services Among Children With ASD. Pediatrics,

543 137(Supplement), S176-S185. http://doi.org/10.1542/peds.2015-2851P

544 Burns, K. H., Casey, P. H., Lyle, R. E., Bird, T. M., Fussell, J. J., \& Robbins, J. M. (2010).

545 Increasing prevalence of medically complex children in US hospitals. Pediatrics, 126(4), 
638-646. http://doi.org/10.1542/peds.2009-1658

Caicedo, C. (2014). Families With Special Needs Children. Journal of the American Psychiatric Nurses Association, 20(6), 398-407. http://doi.org/10.1177/1078390314561326

Cameron, E., Heath, G., Redwood, S., Greenfield, S., Cummins, C., Kelly, D., \& Pattison, H. (2014). Health care professionals' views of paediatric outpatient non-attendance: implications for general practice. Family Practice, 31(1), 111-117. http://doi.org/10.1093/fampra/cmt063

Chiri, G., \& Warfield, M. E. (2012). Unmet need and problems accessing core health care services for children with autism spectrum disorder. Maternal and Child Health Journal, 16(5), 1081-1091. http://doi.org/10.1007/s10995-011-0833-6

Churchill, S. S., Villareale, N. L., Monaghan, T. A., Sharp, V. L., \& Kieckhefer, G. M. (2010). Parents of Children with Special Health Care Needs Who have Better Coping Skills have Fewer Depressive Symptoms. Maternal and Child Health Journal, 14(1), 47-57. http://doi.org/10.1007/s10995-008-0435-0

Creswell, J. W. (2009). Research design : qualitative, quantitative, and mixed methods approaches. Sage.

Data Resource Center for Child and Adolescent Health. (n.d.). National Survey of Children's Health - Data Resource Center for Child and Adolescent Health. Retrieved December 15, 2016, from http://childhealthdata.org/learn/NSCH

DeHoff, B. A., Staten, L. K., Rodgers, R. C., \& Denne, S. C. (2016). The Role of Online Social Support in Supporting and Educating Parents of Young Children With Special Health Care Needs in the United States: A Scoping Review. Journal of Medical Internet Research, 18(12), e333. http://doi.org/10.2196/jmir.6722 
569 Dunlea, R., \& Lenert, L. (2015). Understanding Patients' Preferences for Referrals to Specialists 570 for an Asymptomatic Condition. Medical Decision Making, 35(6), 691-702.

$571 \quad$ http://doi.org/10.1177/0272989X14566640

572 Falkov, A. (2012). The family model handbook: an integrated approach to supporting mentally 573 ill parents and their children. Retrieved from http://www.worldcat.org/title/family-model574 handbook-an-integrated-approach-to-supporting-mentally-ill-parents-and-their$575 \quad$ children/oclc/868958058

576 Ferguson, H. (2016). Researching Social Work Practice Close Up: Using Ethnographic and 577 Mobile Methods to Understand Encounters between Social Workers, Children and Families. 578 British Journal of Social Work, 46(1), 153-168. http://doi.org/10.1093/bjsw/bcu120

579 Findler, L., Klein Jacoby, A., \& Gabis, L. (2016). Subjective happiness among mothers of 580 children with disabilities: The role of stress, attachment, guilt and social support. Research in Developmental Disabilities, 55, 44-54. http://doi.org/10.1016/J.RIDD.2016.03.006

Geist, R., Grdisa, V., \& Otley, A. (2003). Psychosocial issues in the child with chronic conditions. Best Practice \& Research Clinical Gastroenterology, 17(2), 141-152. http://doi.org/10.1016/S1521-6918(02)00142-7

Goudie, A., Narcisse, M.-R., Hall, D. E., \& Kuo, D. Z. (2014). Financial and psychological stressors associated with caring for children with disability. Families, Systems \& Health : The Journal of Collaborative Family Healthcare, 32(3), 280-90. http://doi.org/10.1037/fsh0000027

Health Resources and Services Administration. (2016). Children with Special Health Care Needs I Maternal and Child Health Bureau. Retrieved April 26, 2018, from https://mchb.hrsa.gov/maternal-child-health-topics/children-and-youth-special-health-needs 
592 Kissel, S. D., \& Nelson, W. M. (2016). Parents' Perceptions of the Severity of Their Child's

593 Autistic Behaviors and Differences in Parental Stress, Family Functioning, and Social

594 Support. Focus on Autism and Other Developmental Disabilities, 31(2), 152-160.

$595 \quad$ http://doi.org/10.1177/1088357614537352

596 Krahn, G. L., Walker, D. K., \& Correa-De-Araujo, R. (2015). Persons with disabilities as an

597 unrecognized health disparity population. American Journal of Public Health, 105 Suppl

598 2(Suppl 2), S198-206. http://doi.org/10.2105/AJPH.2014.302182

599 Krauss, M. W., Gulley, S., Sciegaj, M., \& Wells, N. (1993). Access to Specialty Medical Care

600 for Children With Mental Retardation, Autism, and Other Special Health Care Needs.

601 MENTAL RETARDATION Horowitz \& Stein Ireys, 41(5), 329-339. Retrieved from

602 https://pdfs.semanticscholar.org/af4a/c7fe705cee6f495c4a3e7e5e394883855d1c.pdf

603 Kuhlthau, K., Kahn, R., Hill, K. S., Gnanasekaran, S., \& Ettner, S. L. (2010). The Well-Being of

604 Parental Caregivers of Children with Activity Limitations. Maternal and Child Health

605 Journal, 14(2), 155-163. http://doi.org/10.1007/s10995-008-0434-1

606 Kuo, D. Z., \& Houtrow, A. J. (2016). Recognition and Management of Medical Complexity.

607 PEDIATRICS, 138(6), e20163021-e20163021. http://doi.org/10.1542/peds.2016-3021

608 Kuo, D. Z., Houtrow, A. J., Arango, P., Kuhlthau, K. A., Simmons, J. M., \& Neff, J. M. (2012).

609 Family-Centered Care: Current Applications and Future Directions in Pediatric Health Care.

610 Maternal and Child Health Journal, 16(2), 297-305. http://doi.org/10.1007/s10995-011-

$611 \quad 0751-7$

612 Langford, C. P. H., Bowsher, J., Maloney, J. P., \& Lillis, P. P. (1997). Social support: a

613 conceptual analysis. Journal of Advanced Nursing, 25(1), 95-100.

$614 \quad$ http://doi.org/10.1046/j.1365-2648.1997.1997025095.x 
615 McKenzie, K., Ouellette-Kuntz, H., Blinkhorn, A., \& Démoré, A. (2017). Out of School and Into

616 Distress: Families of Young Adults with Intellectual and Developmental Disabilities in

617 Transition. Journal of Applied Research in Intellectual Disabilities, 30(4), 774-781.

618 http://doi.org/10.1111/jar.12264

619 McPherson, M., Arango, P., Fox, H., Lauver, C., McManus, M., Newacheck, P. W., ...

620 Strickland, B. (1998). A New Definition of Children With Special Health Care Needs.

621 Pediatrics, 102(1). Retrieved from

622 http://pediatrics.aappublications.org/content/102/1/137.short

623 Miles, M. B., \& Huberman, A. M. (1994). Qualitative data analysis : an expanded sourcebook.

624 Sage Publications. Retrieved from

625 https://books.google.com/books/about/Qualitative_Data_Analysis.html?id=U4lU_-wJ5QEC

626 Miles, M. B., Huberman, A. M., \& Saldaña, J. (2013). Qualitative data analysis : a methods

$627 \quad$ sourcebook. Sage.

628 National Academy of Sciences. (2017). Improving Health Outcomes for Children with

629 Disabilities : Health and Medicine Division. Retrieved April 30, 2018, from

$630 \mathrm{http} / / /$ nationalacademies.org/hmd/activities/selectpops/improvinghealthoutcomesforchildren

$631 \quad$ withdisabilities.aspx

632 Neece, C. L. (2014). Mindfullness based stress reduction for parental mental health and child

633 behavior problems. Journal of Applied Research in Intellectual Disabilities, 117(1), 174-

634 186. http://doi.org/10.1352/1944-7558-117.1.48

635 Neves, E. T., Cabral, I. E., Silveira, A. da, Neves, E. T., Cabral, I. E., \& Silveira, A. da. (2013).

636 Family network of children with special health needs: implications for Nursing. Revista

637 Latino-Americana de Enfermagem, 21(2), 562-570. http://doi.org/10.1590/S0104- 
638

639

640

641

642

643

644

645

646

647

648

649

650

651

652

653

654

655

656

657

658

659

660

\section{3}

Norona, A. N., \& Baker, B. L. (2014). The transactional relationship between parenting and emotion regulation in children with or without developmental delays. Research in Developmental Disabilities, 35(12), 3209-3216. http://doi.org/10.1016/J.RIDD.2014.07.048

Okumura, M. J., Hersh, A. O., Hilton, J. F., \& Lotstein, D. S. (2013). Change in Health Status and Access to Care in Young Adults With Special Health Care Needs: Results From the 2007 National Survey of Adult Transition and Health. Journal of Adolescent Health, 52(4), 413-418. http://doi.org/10.1016/J.JADOHEALTH.2012.08.005

Peer, J. W., \& Hillman, S. B. (2014). Stress and Resilience for Parents of Children With Intellectual and Developmental Disabilities: A Review of Key Factors and Recommendations for Practitioners. Journal of Policy and Practice in Intellectual Disabilities, 11(2), 92-98. http://doi.org/10.1111/jppi.12072

Pollard, R. Q., Betts, W. R., Carroll, J. K., Waxmonsky, J. a, Barnett, S., Degruy, F. V, ... Kellar-Guenther, Y. (2014). Integrating primary care and behavioral health with four special populations: Children with special needs, people with serious mental illness, refugees, and deaf people. The American Psychologist, 69(4), 377-87. http://doi.org/10.1037/a0036220

Pridham, K., Limbo, R., \& Schroeder, M. (1998). Support of Family Caregiving for Children with Special Needs. Retrieved from http://parenthood.library.wisc.edu/Pridham/Pridham.html

Reichman, N. E., Corman, H., \& Noonan, K. (2008). Impact of Child Disability on the Family. Maternal and Child Health Journal, 12(6), 679-683. http://doi.org/10.1007/s10995-0070307-z

Resch, J. A., Mireles, G., Benz, M. R., Grenwelge, C., Peterson, R., \& Zhang, D. (2010). Giving 
661

662

663

664

665

666

667

668

669

670

671

672

673

674

675

676

677

678

679

680

681

682

683

parents a voice: A qualitative study of the challenges experienced by parents of children with disabilities. Rehabilitation Psychology, 55(2), 139-50.

http://doi.org/10.1037/a0019473

Rosen-Reynoso, M., Porche, M. V., Kwan, N., Bethell, C., Thomas, V., Robertson, J., ... Palfrey, J. (2016). Disparities in Access to Easy-to-Use Services for Children with Special Health Care Needs. Maternal and Child Health Journal, 20(5), 1041-1053. http://doi.org/10.1007/s10995-015-1890-z

Schieve, L. A., Gonzalez, V., Boulet, S. L., Visser, S. N., Rice, C. E., Braun, K. V. N., \& Boyle, C. A. (2012). Concurrent medical conditions and health care use and needs among children with learning and behavioral developmental disabilities, National Health Interview Survey, 2006-2010. Research in Developmental Disabilities, 33(2), 467-476. http://doi.org/10.1016/j.ridd.2011.10.008

Silverberg, J. I., Joks, R., \& Durkin, H. G. (2014). Allergic disease is associated with epilepsy in childhood: a US population-based study. Allergy, 69(1), 95-103. http://doi.org/10.1111/all.12319

Stille, C. J., Fischer, S. H., La Pelle, N., Dworetzky, B., Mazor, K. M., \& Cooley, W. C. (2013). Parent Partnerships in Communication and Decision Making About Subspecialty Referrals for Children With Special Needs. Academic Pediatrics, 13(2), 122-132. http://doi.org/10.1016/J.ACAP.2012.12.003

U.S. Department of Health and Human Services - Health Resources and Services Administration - Maternal and Child Health Bureau. (2013). The National Survey of Children with Special Health Care Needs: Chartbook 2009-2010, (June), 1-109.

US Department of Health and Human Services. (1987). Children with special health care needs. 
684

685

686

687

688

689

690

691

692

693

Campaign “87. Surgeon General”s Report. Commitment to: Family-Centered, CommunityBased, Coordinated Care. Rockville, MD: Retrieved from

https://profiles.nlm.nih.gov/NN/B/C/F/P/_/nnbcfp.pdf

Van Cleave, J. (2015). Children with special health care needs: with population-based data, better individual care plans. Pediatrics, 135(4), e1040-1. http://doi.org/10.1542/peds.20150319

van Dijk, C. E., Korevaar, J. C., Koopmans, B., de Jong, J. D., \& de Bakker, D. H. (2014). The primary-secondary care interface: Does provision of more services in primary care reduce referrals to medical specialists? Health Policy, 118(1), 48-55. http://doi.org/10.1016/J.HEALTHPOL.2014.04.001

Woodman, A. C., \& Hauser-Cram, P. (2013). The role of coping strategies in predicting change in parenting efficacy and depressive symptoms among mothers of adolescents with developmental disabilities. Journal of Intellectual Disability Research, 57(6), 513-530. http://doi.org/10.1111/j.1365-2788.2012.01555.x

Zaidman-Zait, A., Mirenda, P., Duku, E., Vaillancourt, T., Smith, I. M., Szatmari, P., ... Thompson, A. (2017). Impact of personal and social resources on parenting stress in mothers of children with autism spectrum disorder. Autism, 21(2), 155-166. http://doi.org/10.1177/1362361316633033

Zuckerman, K. E., Lindly, O. J., Bethell, C. D., \& Kuhlthau, K. (2014). Family Impacts Among Children With Autism Spectrum Disorder: The Role of Health Care Quality. Academic Pediatrics, 14(4), 398-407. http://doi.org/10.1016/j.acap.2014.03.011 


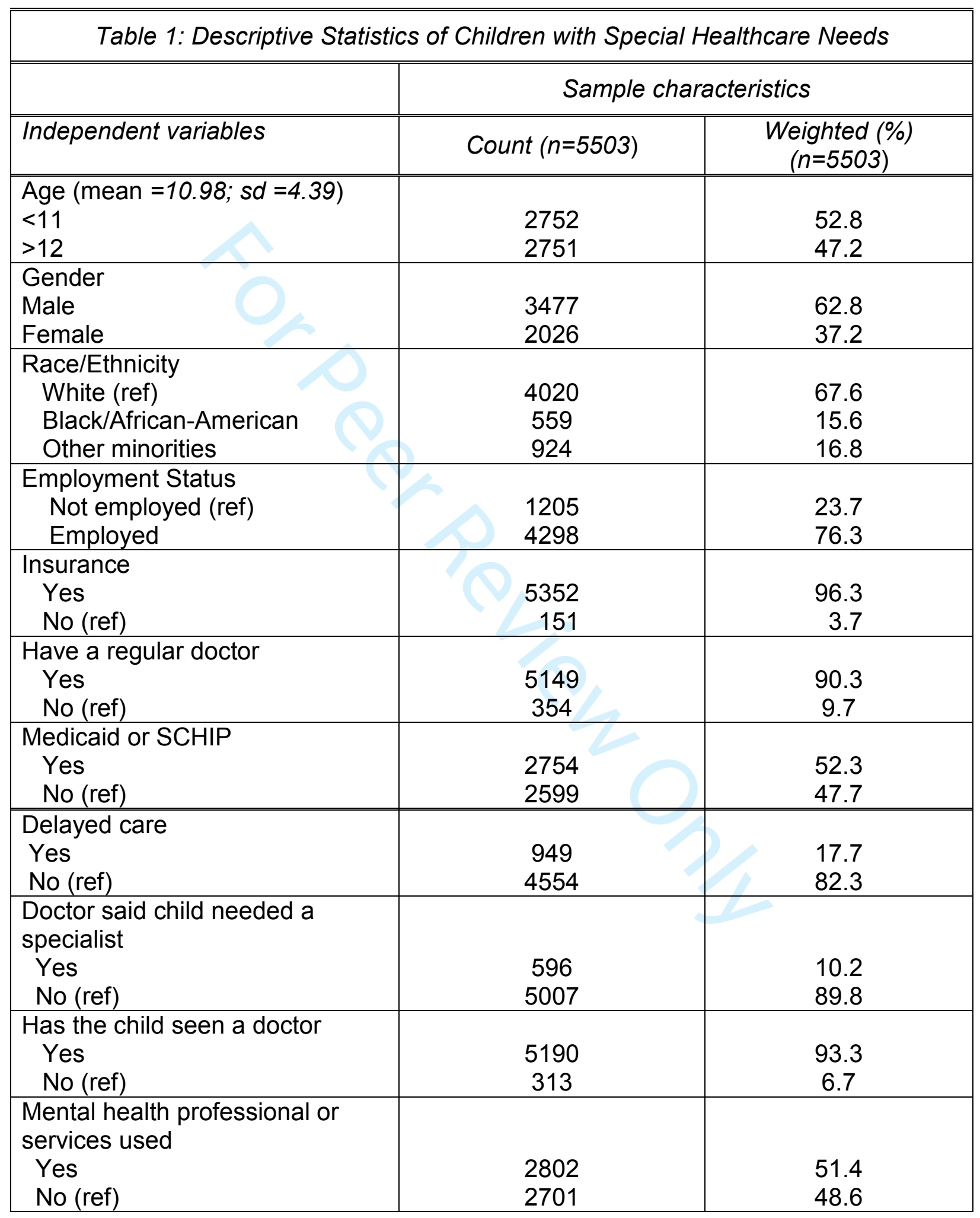




\begin{tabular}{|c|c|c|}
\hline $\begin{array}{l}\text { Child with special health care } \\
\text { need } \\
\text { Yes } \\
\text { No (ref) }\end{array}$ & $\begin{array}{c}4855 \\
648\end{array}$ & $\begin{array}{l}86.7 \\
13.3 \\
\end{array}$ \\
\hline $\begin{array}{l}\text { Child needs treatment or } \\
\text { counseling } \\
\text { Yes } \\
\text { No (ref) }\end{array}$ & $\begin{array}{l}1779 \\
3724\end{array}$ & $\begin{array}{l}34.3 \\
65.7\end{array}$ \\
\hline $\begin{array}{l}\text { Does the child have a behavio } \\
\text { problem } \\
\text { Yes } \\
\text { No (ref) }\end{array}$ & $\begin{array}{l}1301 \\
4202\end{array}$ & $\begin{array}{l}28.5 \\
71.5\end{array}$ \\
\hline $\begin{array}{l}\text { Does the child have autism } \\
\text { Yes } \\
\text { No (ref) }\end{array}$ & $\begin{array}{l}1623 \\
3880\end{array}$ & $\begin{array}{l}28.7 \\
71.3\end{array}$ \\
\hline $\begin{array}{l}\text { Developmental delay } \\
\text { Yes } \\
\text { No (ref) }\end{array}$ & $\begin{array}{l}3111 \\
2392\end{array}$ & $\begin{array}{l}56.8 \\
43.2\end{array}$ \\
\hline $\begin{array}{l}\text { Intellectual delay } \\
\text { Yes } \\
\text { No (ref) }\end{array}$ & $\begin{array}{c}933 \\
4570\end{array}$ & $\begin{array}{l}15.2 \\
84.8 \\
\end{array}$ \\
\hline $\begin{array}{l}\text { Positive parental coping with } \\
\text { parenthood } \\
\text { Yes } \\
\text { No (ref) }\end{array}$ & $\begin{array}{c}5193 \\
310\end{array}$ & $\begin{array}{c}92.8 \\
7.2\end{array}$ \\
\hline $\begin{array}{l}\text { Family problems paying bills } \\
\text { Yes } \\
\text { No (ref) }\end{array}$ & $\begin{array}{l}1241 \\
4262\end{array}$ & $\begin{array}{l}24.9 \\
75.1\end{array}$ \\
\hline $\begin{array}{l}\text { Parental social support } \\
\text { Yes } \\
\text { No (ref) }\end{array}$ & $\begin{array}{c}762 \\
4741\end{array}$ & $\begin{array}{l}16.5 \\
83.5 \\
\end{array}$ \\
\hline $\begin{array}{l}\text { Frustration } \\
\text { Yes } \\
\text { No (ref) }\end{array}$ & $\begin{array}{l}2458 \\
3045\end{array}$ & $\begin{array}{l}44.7 \\
55.3 \\
\end{array}$ \\
\hline
\end{tabular}




\begin{tabular}{|c|c|c|c|c|c|c|}
\hline & \multicolumn{4}{|c|}{ Bivariate Analysis } & \multicolumn{2}{|c|}{ Multivariate Analysis } \\
\hline $\begin{array}{l}\text { Independent } \\
\text { variables }\end{array}$ & $\begin{array}{l}\text { Weight } \\
\text { (Yes \%) }\end{array}$ & $\chi^{2}$ & $\overline{O R}$ & $95 \% \mathrm{Cl}$ & OR & $95 \% \mathrm{Cl}$ \\
\hline $\begin{array}{l}\text { Child with special } \\
\text { health care need } \\
\text { Yes } \\
\text { No (ref) }\end{array}$ & $\begin{array}{c}16.5 \\
1.9 \\
\end{array}$ & $11.8^{\star * \star}$ & $\begin{array}{c}2.40^{* * *} \\
1.00 \\
\end{array}$ & $\begin{array}{c}1.44-4.02 \\
--\end{array}$ & $\begin{array}{c}2.00^{*} \\
--\end{array}$ & $\begin{array}{c}1.10-3.61 \\
--\end{array}$ \\
\hline $\begin{array}{l}\text { Child needs } \\
\text { treatment or } \\
\text { counseling } \\
\text { Yes } \\
\text { No (ref) }\end{array}$ & $\begin{array}{l}8.5 \\
9.2\end{array}$ & $20.9^{* \star *}$ & $\begin{array}{c}2.00^{* * *} \\
1.00\end{array}$ & $\begin{array}{c}1.48-2.70 \\
--\end{array}$ & $\begin{array}{c}1.81^{*} \\
--\end{array}$ & $1.08-3.04$ \\
\hline $\begin{array}{l}\text { Doctor said child } \\
\text { needed a specialist } \\
\text { Yes } \\
\text { No (ref) }\end{array}$ & $\begin{array}{c}4.0 \\
13.7\end{array}$ & $41.3^{* \star *}$ & $\begin{array}{c}3.65^{\star * *} \\
1.00\end{array}$ & $\begin{array}{c}2.41-5.54 \\
--\end{array}$ & $\begin{array}{c}3.09^{* * *} \\
--\end{array}$ & 2.03-4.71 \\
\hline $\begin{array}{l}\text { Does the child have } \\
\text { a behavior problem } \\
\text { Yes } \\
\text { No (ref) }\end{array}$ & $\begin{array}{c}6.3 \\
11.4\end{array}$ & $6.68^{* *}$ & $\begin{array}{c}1.51^{* *} \\
1.00\end{array}$ & $\begin{array}{c}1.10-2.06 \\
--\end{array}$ & $\begin{array}{c}0.84 \\
--\end{array}$ & $\begin{array}{c}0.56-1.25 \\
--\end{array}$ \\
\hline $\begin{array}{l}\text { Mental health } \\
\text { professional or } \\
\text { services used } \\
\text { Yes } \\
\text { No (ref) }\end{array}$ & $\begin{array}{c}10.4 \\
7.3\end{array}$ & $6.09^{*}$ & $\begin{array}{c}0.69^{* *} \\
1.00\end{array}$ & $\begin{array}{c}0.51-0.93 \\
-\end{array}$ & $\begin{array}{c}1.09 \\
--\end{array}$ & $\begin{array}{c}0.76-1.55 \\
--\end{array}$ \\
\hline $\begin{array}{l}\text { Does the child have } \\
\text { autism } \\
\text { Yes } \\
\text { No (ref) }\end{array}$ & $\begin{array}{c}5.8 \\
11.9\end{array}$ & 2.16 & $\begin{array}{l}1.27 \\
1.00\end{array}$ & $\begin{array}{c}0.92-1.75 \\
--\end{array}$ & $1.57^{*}$ & $\begin{array}{c}1.06-2.32 \\
--\end{array}$ \\
\hline $\begin{array}{l}\text { Developmental } \\
\text { delay } \\
\text { Yes } \\
\text { No (ref) }\end{array}$ & $\begin{array}{l}9.4 \\
8.4\end{array}$ & 1.63 & $\begin{array}{l}0.83 \\
1.00\end{array}$ & $\begin{array}{c}0.61-1.11 \\
--\end{array}$ & $\begin{array}{c}1.01 \\
--\end{array}$ & $\begin{array}{c}0.59-1.74 \\
--\end{array}$ \\
\hline $\begin{array}{l}\text { Intellectual delay } \\
\text { Yes } \\
\text { No (ref) }\end{array}$ & $\begin{array}{c}2.9 \\
14.8\end{array}$ & 0.34 & $\begin{array}{l}1.12 \\
1.00\end{array}$ & $\begin{array}{c}0.75-1.68 \\
--\end{array}$ & $\begin{array}{l}1.07 \\
--\end{array}$ & $\begin{array}{c}0.59-1.25 \\
--\end{array}$ \\
\hline
\end{tabular}

Note: All percentages are weighted proportions; Significance levels: * $p<0.05,{ }^{* *} p<0.01$ and ${ }^{* *} p<0.001$ 


\begin{tabular}{|c|c|c|c|c|c|c|}
\hline \multirow[b]{2}{*}{$\begin{array}{l}\text { Independent } \\
\text { variables }\end{array}$} & \multicolumn{4}{|c|}{ Bivariate Analysis } & \multicolumn{2}{|c|}{ Multivariate Analysis } \\
\hline & $\begin{array}{l}\text { Weig } \\
\text { hted } \\
\text { (Yes } \\
\%) \\
\end{array}$ & $\chi^{2}$ & OR & $95 \% \mathrm{Cl}$ & OR & $95 \% \mathrm{Cl}$ \\
\hline $\begin{array}{l}\text { Employment } \\
\text { Status } \\
\text { Yes } \\
\text { No (ref) }\end{array}$ & $\begin{array}{c} \\
12.0 \\
5.7\end{array}$ & $45.0^{\star * *}$ & $\begin{array}{c}0.60^{* *} \\
1.00\end{array}$ & $\begin{array}{c}0.43-0.83 \\
--\end{array}$ & $\begin{array}{c}0.71 \\
--\end{array}$ & $\begin{array}{c}0.46-1.05 \\
--\end{array}$ \\
\hline $\begin{array}{l}\text { Insurance } \\
\text { Yes } \\
\text { No (ref) }\end{array}$ & $\begin{array}{c}16.2 \\
1.5\end{array}$ & $12.7^{* * *}$ & $\begin{array}{c}0.29^{* * *} \\
1.00\end{array}$ & $\begin{array}{c}0.14-0.60 \\
--\end{array}$ & $\begin{array}{c}0.34^{* *} \\
--\end{array}$ & $\begin{array}{c}0.15-0.73 \\
--\end{array}$ \\
\hline $\begin{array}{l}\text { Medicaid or } \\
\text { SCHIP } \\
\text { Yes } \\
\text { No (ref) }\end{array}$ & $\begin{array}{c}10.2 \\
7.5 \\
\end{array}$ & 3.11 & $\begin{array}{l}1.30 \\
1.00 \\
\end{array}$ & $\begin{array}{c}0.97-1.74 \\
--\end{array}$ & $\begin{array}{c}1.96^{* * *} \\
--\end{array}$ & $\begin{array}{c}1.32-2.92 \\
--\end{array}$ \\
\hline $\begin{array}{l}\text { Have a regular } \\
\text { doctor } \\
\text { Yes } \\
\text { No (ref) }\end{array}$ & $\begin{array}{c}15.9 \\
1.8\end{array}$ & 0.06 & $\begin{array}{l}0.94 \\
1.00\end{array}$ & $\begin{array}{c}0.58-.1 .54 \\
--\end{array}$ & $\begin{array}{c}1.70 \\
--\end{array}$ & $\begin{array}{c}0.98-2.93 \\
--\end{array}$ \\
\hline $\begin{array}{l}\text { Has the child } \\
\text { seen a doctor } \\
\text { Yes } \\
\text { No (ref) }\end{array}$ & $\begin{array}{l}16.8 \\
0.96\end{array}$ & 0.84 & $\begin{array}{l}1.30 \\
1.00\end{array}$ & $\begin{array}{c}0.73-2.31 \\
--\end{array}$ & $\begin{array}{c}1.91 \\
--\end{array}$ & $\begin{array}{c}0.92-3.94 \\
--\end{array}$ \\
\hline
\end{tabular}

Note: All percentages are weighted proportions; Significance levels: * $p<0.05,{ }^{* *} p<0.01$ and ${ }^{* * *} p<0.001$ 


\begin{tabular}{|c|c|c|c|c|c|c|}
\hline \multirow[b]{2}{*}{$\begin{array}{l}\text { Independent } \\
\text { variables }\end{array}$} & \multicolumn{4}{|c|}{ Bivariate Analysis } & \multicolumn{2}{|c|}{ Multivariate Analysis } \\
\hline & $\begin{array}{l}\text { Weight } \\
\text { (Yes \%) }\end{array}$ & $\chi^{2}$ & OR & $95 \% \mathrm{Cl}$ & $\overline{O O R}$ & $95 \% \mathrm{Cl}$ \\
\hline $\begin{array}{l}\text { Positive coping } \\
\text { with parenthood } \\
\text { Yes } \\
\text { No (ref) }\end{array}$ & $\begin{array}{c}15.7 \\
2.0 \\
\end{array}$ & $5.43^{*}$ & $\begin{array}{c}0.52^{*} \\
1.00\end{array}$ & $\begin{array}{c}0.30-0.91 \\
--\end{array}$ & $\begin{array}{c}0.86 \\
--\end{array}$ & $\begin{array}{c}0.48-1.53 \\
--\end{array}$ \\
\hline $\begin{array}{l}\text { Family problems } \\
\text { paying medical } \\
\text { bills } \\
\text { Yes } \\
\text { No (ref) }\end{array}$ & $\begin{array}{l}8.8 \\
8.9\end{array}$ & $82.1^{\star * \star}$ & $\begin{array}{c}4.11^{* * *} \\
1.00\end{array}$ & $\begin{array}{c}2.99-5.66 \\
--\end{array}$ & $\begin{array}{c}2.17^{\star \star \star} \\
--\end{array}$ & $\begin{array}{c}1.52-3.09 \\
--\end{array}$ \\
\hline $\begin{array}{l}\text { Parental social } \\
\text { support } \\
\text { Yes } \\
\text { No (ref) }\end{array}$ & $\begin{array}{c}13.8 \\
3.9\end{array}$ & $6.22^{*}$ & $\begin{array}{c}0.64^{* *} \\
1.00\end{array}$ & $\begin{array}{c}0.45-0.91 \\
--\end{array}$ & $\begin{array}{c}0.95 \\
--\end{array}$ & $\begin{array}{c}0.63-1.43 \\
--\end{array}$ \\
\hline $\begin{array}{l}\text { Frustration } \\
\text { Yes } \\
\text { No (ref) }\end{array}$ & $\begin{array}{c}15.3 \\
2.4\end{array}$ & $0.65^{\star * \star}$ & $10.4^{* * *}$ & $\begin{array}{c}6.80-15.8 \\
--\end{array}$ & $\begin{array}{c}7.68^{* * *} \\
--\end{array}$ & $\begin{array}{c}5.06-11.6 \\
--\end{array}$ \\
\hline
\end{tabular}

Note: All percentages are weighted proportions; Significance levels: ${ }^{*} p<0.05,{ }^{* *} p<0.01$ and ${ }^{* * *} p<0.001$ 


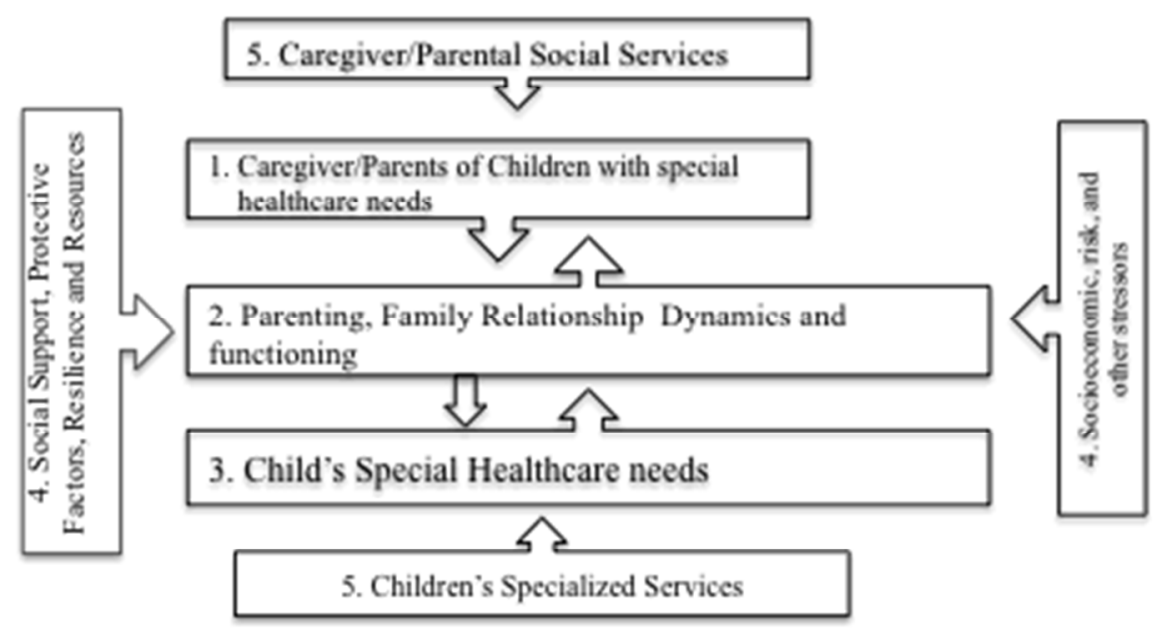

6. External Factors

Culture and Community Services 